\title{
Inhibitory Deficits, Delay Aversion and Preschool AD/HD: Implications for the Dual Pathway Model
}

\author{
Lindy Dalen, Edmund J.S. Sonuga-Barke, Martin Hall and Bob Remington \\ Developmental Brain-Behaviour Unit, Department of Psychology \\ University of Southampton, Highfield, Southampton, England
}

\section{SUMMARY}

The dual pathway model proposes the existence of separate and neurobiologically distinct cognitive (inhibitory and more general executive dysfunction) and motivational (delay aversion) developmental routes to $\mathrm{AD} / \mathrm{HD}$. The study reported in this paper explores the relation between inhibitory deficits and delay aversion and their association with AD/HD in a group of three-year-old children. Children identified as having a pre-school equivalent of AD/HD $(N=19)$ and controls $(N=19)$, matched for gender and IQ, completed a battery of inhibition and delay tasks. Correlational and factor analysis supported a dissociation between inhibitory deficits (go-no-go, set shifting) and delay aversion (choice delay) with delay of gratification cross-loading. Children with $\mathrm{AD} / \mathrm{HD}$ displayed more inhibitory deficits and were more delay averse than controls. The data support the value of the distinction between motivational and cognitive pathways to AD/HD. Furthermore, the data suggest that such a distinction is apparent relatively early on during development.

Reprint requests to: Lindy Dalen, Centre for Research into Psychological Development. Department of Psychology, University of Southampton, Highfield, Southampton, England SO17 1BJ; e-mail:

\section{INTRODUCTION}

Neurocognitive accounts typically portray attention deficit/hyperactivity disorder (AD/HD) as a fronto-neostriatal disorder (Casey et al., 2002; Giedd et al., 2001) associated with deficient impulse control and executive functions (for example, Barkley, 1997; Barnett et al., 2001; Bayliss \& Roodenrys, 2000). Although this definition represents the majority view among researchers, alternative accounts of the condition have been proposed (Castellanos \& Tannock, 2002; SonugaBarke, 2002). For example, one motivationally based account presents $\mathrm{AD} / \mathrm{HD}$ as the result of hypersensitivity to reward-related delay (Sagvolden et al., 1998), underpinned by alterations within fronto-accumbal reward circuits (for example, Cardinal et al., 2001; Robbins \& Everitt, 1996). Evidence for this model comes primarily from choice studies where children with $\mathrm{AD} / \mathrm{HD}$ display a greater sensitivity to delay than their peers, choosing smaller sooner (SS) over larger later (LL) rewards (Kuntsi et al., 2001; Schweitzer \& Sulzer-Azaroff, 1995; Solanto et al., 2001; Tripp \& Alsop, 2001). This tendency appears most pronounced when the SS choices reduce overall delay rather than only increasing reward immediacy. As a result, children with $\mathrm{AD} / \mathrm{HD}$ have been described as 'delay averse' rather than 'impulsive' (Sonuga-Barke, 1994; Sonuga-Barke et al., 1992).

Sonuga-Barke $(2002 ; 2003)$ recently proposed a reconciliation of these two accounts in which 
AD/HD develops along two separate pathways: $A$ cognitive pathway mediated at the psychological level by executive dysfunction, and a motivational pathway mediated by delay sensitivity/aversion. This formulation was in part motivated by a recent head-to-head study in which the models were pitted against each other (Solanto et al., 2001). Children with combined-type AD/HD and controls performed the stop signal task (in which a response already initiated is inhibited following a 'stop' signal) and a choice delay task involving a series of irreversible choices between LL and SS rewards. Although inhibitory deficits and delay sensitivity were uncorrelated, performance on both tasks was strongly associated with $\mathrm{AD} / \mathrm{HD}$ group membership. In combination, the two measures allowed just under 90 percent of the $\mathrm{AD} / \mathrm{HD}$ children to be correctly classified.

The results of this study raised the possibility of distinct motivational and cognitive bases for $\mathrm{AD} / \mathrm{HD}$, which is therefore consistent with a dual developmental pathway model of $\mathrm{AD} / \mathrm{HD}$. Claims of the existence of separate developmental pathways, however, can be made only once the equivalent distinctions between cognitive and motivational aspects of the condition have been established at different developmental stages.

The study reported in this paper examines the early manifestation of the motivational and cognitive elements of $\mathrm{AD} / \mathrm{HD}$ in a group of 3-yearold children. This age group was selected because it was judged the earliest developmental stage at which such a study was feasible.

First, at this age AD/HD type behaviors are already identified as posing a distinct clinical problem (Connor, 2002). Even when diagnosed after school-entry, AD/HD typically has an early onset (often by 3 years) associated with significant impairment (Sonuga-Barke et al., 2003). There are strong continuities from this period to school in symptom structure, expression, and associated psychological and family disturbance (Barkley et al., 2002; Lahey et al., 1998; Sonuga-Barke et al.,
1997; Wilens et al., 2002). Second, inhibitory control and rudimentary executive functions have already started to emerge by this age and can be reliably measured using modified versions of standardized laboratory procedures (Anderson, 1998; Espy et al., 2001). Third, inhibitory deficits are associated with $\mathrm{AD} / \mathrm{HD}$ type problems by the age of 3 years, even after other associated problems are controlled (Sonuga-Barke et al., 2002; Berlin \& Bohlin, 2002). Interestingly, less evidence is available for deficits in other domains of executive functioning. While Mariani and Barkley (1997) demonstrated an association with working memory, others found that this association disappears once such factors as IQ and conduct problems are controlled (Hughes et al., 2000; Sonuga-Barke et al., 2002).

No study has yet been made of delay aversion and $\mathrm{AD} / \mathrm{HD}$ in the pre-school period. Delay-ofgratification tasks differentiate between hyperactive and non-hyperactive preschoolers (Campbell et al., 1982). These tasks, however, have a large inhibitory component (Reynolds et al., 2002). In the current study, a Choice Delay Task (Solanto et al., 2001) was employed in which the choice of the LL reward is a purer measure of delay sensitivity as it implicates minimal levels of inhibitory control because once the LL choice is made, the child is committed to that outcome and has no opportunity to switch to the SS reward. In order to distinguish between preference for immediacy and delay aversion, the children performed under two conditions. In one condition, choices of SS and LL produced trials of the same overall length. In a second, SS choices reduced trial length compared with LL choices. Preference for SS should be stronger in the second as opposed to the first condition if $\mathrm{AD} / \mathrm{HD}$ children are to be described as delay averse.

Three tasks with high inhibitory loadings were also included: a go-no-go inhibition, a set-shift inhibition, and a delay of gratification task. The predictions were as follows. First, delay aversion 
would be dissociated from performance on inhibition tasks. Second, delay of gratification would be associated with both delay aversion and disinhibition. Third, AD/HD children would display more delay aversion and poorer inhibitory control than control subjects.

\section{EXPERIMENTAL}

\section{Subjects}

Nineteen three-year-old children with a preschool equivalent of $\mathrm{AD} / \mathrm{HD}$ and nineteen controls were included in the analysis. There are considerable uncertainties around the use of DSMIV criteria to diagnose pre-school $\mathrm{AD} / \mathrm{HD}$. The referral of pre-schoolers with $\mathrm{AD} / \mathrm{HD}$, given its infrequency, is particularly likely to be skewed by idiosyncratic factors. To avoid these problems, we employed a non-DSM referenced two-stage community-based selection and assessment procedure similar to that used by us in previous studies of preschool children (Sonuga-Barke et al., 2001; Sonuga-Barke et al., 2002). In stage one, health visitors identified children who they felt displayed severe and significantly debilitating levels of inattention, impulsiveness, and hyperactivity. This judgment was based on information gathered during a structured one-to-one consultation with parents, which involved an informal observation of the child's behavior. The parents of the identified children were then interviewed using the Parental Account of Childhood Symptoms (PACS; Taylor et al., 1991). The PACS is a structured clinical interview, developed in the United Kingdom, to assess the core symptoms of $\mathrm{AD} / \mathrm{HD}$ and Conduct Problems (Sonuga-Barke et al., 1994). Parents describe the severity and frequency of symptoms across a range of situations (for example, in the home, with friends, in public) over the previous 6 months. Trained interviewers rate these descriptions using criteria previously validated against clinical judgment. The PACS used in the current study was a slightly modified version of that developed for older children. One item deemed age inappropriate was dropped (lying), and the coding criteria were modified to reflect developmental expectations. The preschool PACS has good psychometric properties. Interrater coefficients of between .92 and .98 and testretest stability over a 15 week period of .78 for $\mathrm{AD} / \mathrm{HD}$ have been reported (Sonuga-Barke et al., 1994). The AD/HD-scale scores have been shown to correlate highly with levels of off-task and inattentive behavior in a free-play situation; discriminate between problems of clinical and nonclinical significance (Sonuga-Barke et al., 2002), and correlate with scores on the hyperactivity scales of the Strengths and Difficulties Questionnaire (Goodman, 1997) and the Behavior Checklist (Gardner et al., 1999).

The children were classified as having AD/HD if they met standard cut-offs (a score of 18 or more). This diagnostic criterion was stringent and equivalent to those required for a diagnosis of combined type $\mathrm{AD} / \mathrm{HD}$ using the DSM-IV criteria in terms of symptom profile (inattention, impulsiveness, and overactivity), severity (scoring above the 95th percentile), pervasiveness (at home, with friends etc.), and duration (previous 6 months). The severity of symptoms in the clinical group was confirmed by the finding that their PACS AD/HD scores were on average five standard deviations higher than those of controls (control mean $=9.31$; $\mathrm{AD} / \mathrm{HD}$ mean $=20.91-$ (pooled standard deviation) $=2.05 ; \mathrm{t}(36)=17.16 ; \mathrm{p}<0.0001)$.

Control subjects were selected from a random sample of 40 children who were regarded as being free from $A D / H D$. The control children were selected to match those in the AD/HD group for gender and approximate IQ level. The IQ was measured using the British Abilities Scales (BAS), which is a widely used and psychometrically sound measure of cognitive ability. The BAS allows the calculation of a score for verbal, visual, 
and general IQ. A short form, which was employed in the current study, includes especially reliable items from across both the visual and the verbal domains (recall of digits; similarities; matrices and speed of information processing). The scores from this short form correlate highly with full-scale scores. The $\mathrm{AD} / \mathrm{HD}$ and control groups did not differ in terms of age (months), (control mean $=$ 38.9: $\mathrm{AD} / \mathrm{HD}$ mean $=39.4 ; \mathrm{t}(36)=-.28 ; \mathrm{p}>.90)$ or IQ (controls $=100.8: \mathrm{AD} / \mathrm{HD}=99.9 ; \mathrm{t}(36)=$ $.51 ; \mathrm{p}>.6)$. There was a trend toward higher conduct problem scores for children with $\mathrm{AD} / \mathrm{HD}$ (control mean $=13.00 ; \mathrm{AD} / \mathrm{HD}$ mean $=15.4 ; \mathrm{t}(36)$ $=1.81 ; \mathrm{p}<0.1)$.

\section{Measures and procedure}

Go-No-Go Inhibition-'Puppet Says ...' Task. Based on the measure adapted by Kochanska et al. (1996) and from Reed et al. (1984), this task involves suppressing or initiating an activity to a signal. Two hand puppets, a policeman and a princess, request the child to perform actions (for example, touch your tummy). The child is required to perform the movement requested by one of the puppets and not by the other. The children were given the following instructions.

Here are two puppets, Policeman Pete and

Princess Pearl. In this game, if Princess

Pearl asks you to do something you must

do it. Let's try (demonstrate using a simple request). If Policeman Pete asks you to do something you must not do it. Let's try.

This instruction was repeated using both puppets requesting different actions. The 'operative' puppet was counterbalanced so that either puppet could be permissive or inhibitory. The children were tested on 16 requests, half of which were inhibitory. Only the latter 8 responses were coded, and for each response, the children scored 2 if they fully inhibited their response, 1 if their response was partially inhibited, and 0 if there was no inhibition. A partially inhibited response involved a movement that although initiated was inhibited before being fully completed. This task correlates highly with other tests of inhibition and maternal ratings of inhibitory capacities and has good levels of test retest reliability.

Delay Aversion-preschool choice delay task: This is an adaptation on the choice delay task developed by Sounga-Barke et al. (1992). Children made repeated choices between SS (1 reward after 1-sec.) and LL (2 rewards after 17-sec.). The rewards were small sweets. The choice options were represented on a computer screen as two teddies carrying balloons. The SS teddy held one balloon and was drawn so that it appeared to be positioned in the foreground of the screen. The LL teddy held two balloons and appeared to be in the background. Depth cues were provided by drawings of paths on which the teddies stood.

Children made their choice between LL and SS by pressing the touch screen 'over' the tummy of the appropriate teddy. When either teddy was activated, it 'walked' to the front of the screen and released the balloon(s), at which point the reward was delivered by the experimenter. There were two conditions. In the PRD condition, delay followed the delivery of rewards (1-sec for the LL and $17 \mathrm{sec}$ for the SS) so equalizing the length of the SS and LL trials at $18 \mathrm{sec}$. In the N-PRD condition, there was no post-reward delay so that the next trial followed immediately after the delivery of rewards. Each condition consisted of 22 trials, and the order of the presentation of conditions was counterbalanced to control for order effects. The first two trials were used to describe the two choice options. During these trials the experimenter said,

This is a choosing game. Here are two teddies. This one is holding one balloon, if you choose him I will give you one of the sweets you told me you liked (demonstrate). This one is holding two balloons, if you 
choose him I will give you two sweets but you have to wait for him to walk all the way to the front before you get your sweets (demonstrate).

If the child was in the PRD condition, then the experimenter asked the child to watch what happened after the delivery of the rewards and then confirmed to the child that

Yes if you choose the teddy with one balloon you have to wait before he goes back to his starting position at the back of the screen and then you can choose again.

The experimenter then asked the child to make a choice, saying, Which teddy will you choose? There was a short break before the start of the second condition. Again the first two trials were used to explain the task. The experimenter said,

The teddies would like you to do some more choosing and win even more stickers but this time something is different. Let's see if you can tell me what is different.

At the end of the first practice trial, the experimenter confirmed the presence or absence of the PRD by saying, $Y$ es, this time you have to wait/don't have to wait after the rewards are delivered. The test-retest reliability for this task is satisfactory $(r=.67$; Dalen, 2002).

Delay of Gratification-Cookie Delay Task: This task, developed by Golden et al. (1997), involves placing an edible treat under one of three upturned transparent cups and asking the child to wait for a signal (clap) before retrieving the treat. Eight trials were given in a pseudo-random order with delays of between 5 and $30 \mathrm{~s}$. The experimenter's hands were raised at the midpoint (after $10 \mathrm{~s}$ if delay was $20 \mathrm{~s}$ ) ready to clap. The following instructions were given.

In this game I am going to put a sweet under the cup. The sweet is yours, you can have the sweet and you may eat the sweet
BUT in this game I want you to wait until I clap my hands like this (clap hand) before you can get the sweet. Let's try".

There was a single practice trial. If the child moved before the experimenter clapped, the rule was restated so the child understood that (s)he was not to make any movement toward the cup until the clap. The scoring was $0=$ not inhibited, $1=$ partially inhibited and 2 = fully inhibited, so the possible range of scores was $0-16$. The task has been shown to be reliable and to discriminate between hard-to-manage preschoolers and their peers (Campbell et al., 1994).

Set shifting-modified Weigl block sorting task: This task, a modification of the task adapted by De Renz et al. (1966), tests the ability of children to sort blocks according to different rules, inhibiting old rules and shifting to new ones. Twelve blocks that could be sorted on the basis of color ( 3 red, 3 blue, 3 green, 3 yellow), shape ( 4 circles, 4 squares, 4 triangles), size (6 large, 6 small), width (6 thick, 6 thin) and picture ( 3 dogs, 3 bees, 3 clocks, 3 trumpets) were used. At the start of the task, the experimenter discussed the properties of the blocks (colors, shapes etc.) and checked that the child could identify these properties. A shared understanding of naming was established (for example, the use of the term fat/thin, high/low etc).

The experimenter then said, This is a sorting game. Do you know what sorting out means? The principle of sorting was then demonstrated, These things go together because they are the same color/shape.

The experimenter then proceeded,

So you see you can sort these blocks in different ways. I want to see if you can sort the blocks into colors (shapes/sizes/widths/ pictures) that go together.

The children's response was scored a pass if they were correct, or a failure if they could not sort, 
made an error in the sort, or if they sorted on an incorrect characteristic (contrary to instruction). On the final sort, the child was instructed to do an original sort (not do what the experimenter did). The child could pass or fail a maximum of six sorts. The child scored 0 for a failed sort and 2 for each successful sort, giving a range of possible scores from $0-12$, with higher scores indicating greater set shifting ability. Test retest for this task is high $(\underline{r}=.97$; Dalen, 2002).

\section{RESULTS}

\section{Experimental analysis of the Choice Delay Task}

Table 1 shows the proportion of LL choices under PRD and N-PRD conditions. The data were submitted to a three-way ANOVA with condition (post/no-post delay) and block (first 10 trials/ second 10 trials) as within subject factors and group ( $\mathrm{AD} / \mathrm{HD} /$ controls) as between subject factor.

TABLE 1

The proportion of choices for the large delayed reward made by $\mathrm{AD} / \mathrm{HD}$ and control children under post- and no-post-reward delay conditions

\begin{tabular}{|c|c|c|c|c|}
\hline \multirow{2}{*}{ Reward delay } & \multicolumn{2}{|c|}{ Controls } & \multicolumn{2}{c|}{ AD/HD } \\
\cline { 2 - 5 } & Block 1 & Block 2 & Block 1 & Block 2 \\
\cline { 2 - 5 } & Mean (SD) & Mean (SD) & Mean (SD) & Mean (SD) \\
\hline No Post-Delay & $.53(.15)$ & $57(.30)$ & $.37(.18)$ & $.28(.22)$ \\
\hline Post-Delay & $.58(.21)$ & $.64(.24)$ & $.62(.18)$ & $.54(.31)$ \\
\hline
\end{tabular}

TABLE 2

Correlations between delay aversion index, scores on delay of gratification, go-no-go, and set shifting tasks and age, IQ and conduct problems for the whole sample.

\begin{tabular}{|c|c|c|c|c|}
\hline & $\begin{array}{c}\text { 1. Delay } \\
\text { Aversion }\end{array}$ & $\begin{array}{c}\text { 2. Delay of } \\
\text { gratification }\end{array}$ & $\begin{array}{c}\text { 3. Go-no-go } \\
\text { inhibition }\end{array}$ & 4. Set shifting \\
\hline 1 & 1.00 & & & \\
\hline 2 & $-.33^{*}$ & 1.00 & & \\
\hline 3 & -.08 & $.33^{*}$ & 1.00 & $.35^{*}$ \\
\hline 4 & -.13 & .24 & & 1.00 \\
\hline IQ & .08 & .13 & $.51^{*}$ & $.39^{*}$ \\
\hline Age & .20 & -.22 & -.05 & .15 \\
\hline $\begin{array}{c}\text { Conduct } \\
\text { problems }\end{array}$ & -.06 & -.05 & .10 & -.05 \\
\hline
\end{tabular}

Note: Higher scores on the delay aversion index mean more delay aversion. ${ }^{*}=p<0.05$. 


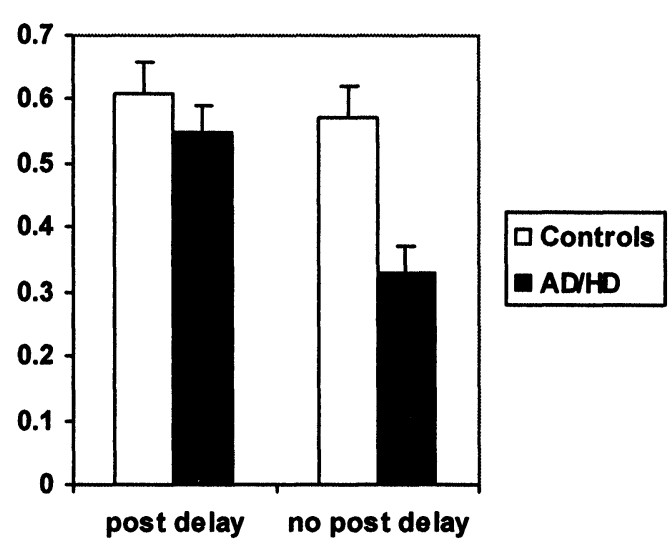

Fig. 1: The differential effect of post-reward delay on preference for the large delayed reward on the choice delay task. Error bars represent standard errors.

There was a significant effect of condition, $\underline{F}(1,36)$ $=13.95 ; \mathrm{p}<0.01$, with more LL chosen in the PRD. There was an effect of group, $\underline{F}(1,36)=$ $7.20 ; p<0.01$ : Controls chose more LL than did children with $\mathrm{AD} / \mathrm{HD}$. Finally there was an interaction between group and condition, $\underline{\mathrm{F}}(1,36)=$ 4.82; $\mathrm{p}<0.05$ (Figure 1). AD/HD children chose more SS under NPRD, $\mathrm{t}(36)=3.87 ; \mathrm{p}<0.01$, but not PRD, $\mathrm{t}(36)=0.52$; ns. More SS were chosen under N-PRD by $\mathrm{AD} / \mathrm{HD}, \mathrm{t}(36)=3.70 ; \mathrm{p}<0.01$, but not control children, $\mathrm{t}(36)=1.29$; ns. This interaction between condition and group remained significant after gender and the presence of conduct problems were controlled for, $\underline{F}(1,34)=$ $4.16 ; p<0.05$. There was no effect of block, block did not interact with condition and there was no three-way interactions between block, condition and group, $\underline{\operatorname{Fs}}(1,36)<0.71$. In order to facilitate tests of associations with other task measures an index of delay aversion (IDA), the tendency to reduce trial length by choosing SS under the N-PRD condition but not under the PRD condition, was created using the formula: LL PRD - LL N-PRD.
The association between inhibitory control and delay aversion. Table 2 shows the pattern of correlations between the IDA and performance on the three other tasks. There was no correlation between the IDA and either go-no-go inhibition and set shifting. These two measures of inhibition were correlated to each other. Scores on the delay of gratification task were correlated with both gono-go inhibition and IDA. The IQ was correlated with go-no-go inhibition and set shifting. Neither age nor conduct problems was associated with task performance. In order to test for the distinction between inhibitory deficits and delay aversion, we submitted the three test scores and the IDA to a principle components factor analysis using a varimax solution giving orthogonal factors. Two factors with eigen values greater than 1 were extracted. The first factor accounted for 44 percent of the overall variance and was labeled 'inhibitory deficit' (loadings - go-no-go inhibition, .78; set shifting, .76; delay of gratification, .61; IDA, -.04). The second factor accounted for 26 percent of the variance and was labeled 'delay aversion' (loadings - go-no-go inhibition, -.11; set shifting, .08 ; delay of gratification, -.56 ; IDA, .93).

\section{Group differences in delay aversion/inhibitory deficits.}

Table 3 shows the mean test and factor scores for children in the AD/HD and control groups. Scores were submitted to a one-way multivariate analysis of variance (MANOVA) with group as the between subject factor. There was a significant overall multivariate effect, $\underline{F}(1,33)=11.34 ; p<$ 0.001 of group. Significant univariate effects were seen for go-no-go inhibition, delay of gratification and the IDA. The effect of group on set shifting approached significance. $\mathrm{AD} / \mathrm{HD}$ children waited less often on the delay of gratification task, made fewer inhibitory responses on the go-no-go task, and had higher scores on the IDA. This association 
TABLE 3

Differences between $\mathrm{AD} / \mathrm{HD}$ and control children on the four tasks and the two derived factor scores

\begin{tabular}{|c|c|c|c|}
\hline \multirow{2}{*}{ Task } & Controls & AD/HD & \\
\cline { 2 - 4 } & Mean (SD) & Mean (SD) & $\underline{\mathrm{F}}$ \\
\hline Go-no-go & $6.10(6.93)$ & $1.59(2.45)$ & $7.16^{*}$ \\
\hline Set shifting & $2.53(1.86)$ & $1.47(1.31)$ & 4.05 \\
\hline Delay of Gratification & $14.24(2.54)$ & $5.00(5.64)$ & $42.32^{*}$ \\
\hline Delay Aversion Index & $0.06(0.25)$ & $0.25(0.21)$ & $4.81^{*}$ \\
\hline Factor I: Inhibition & $0.52(0.95)$ & $-0.52(0.74)$ & $14.52^{*}$ \\
\hline Factor II: Delay Aversion & $-0.47(0.77)$ & $0.47(0.99)$ & $10.72^{*}$ \\
\hline
\end{tabular}

Note; ${ }^{*}=\underline{p}<0.05$; Higher scores on Delay Aversion Index and factor II mean more delay aversion.

of $\mathrm{AD} / \mathrm{HD}$ with both inhibitory deficits and delay aversion was confirmed by an analysis of factor scores. These effects remained after controlling for conduct problems and the gender of child; go-nogo inhibition, $\mathrm{F}(1,34)=7.90 ; \underline{p}<0.01$; set shifting, delay of gratification, $\underline{\mathrm{F}}(1,34)=47.9 ; \mathrm{p}<0.001$; DAI, $\underline{\mathrm{F}}(1,34)=4.16 ; \underline{\mathrm{p}}<0.05$.

\section{DISCUSSION}

This study confirms the previously established link between inhibitory deficits and pre-school AD/HD (for example, Berlin \& Bohlin, 2002). The study provides further support for the idea that inhibitory deficits in $\mathrm{AD} / \mathrm{HD}$ are established very early on during development (Barkley, 1997). At the same time, this study provides the first evidence linking pre-school $\mathrm{AD} / \mathrm{HD}$ with delay aversion independently of inhibitory deficits. By replicating the pattern of results of Solanto et al. (2001), this study supports the view that $\mathrm{AD} / \mathrm{HD}$ is a psychologically heterogeneous disorder with distinct motivational and cognitive elements. The results are therefore consistent with the dual developmental pathway model of $\mathrm{AD} / \mathrm{HD}$. Further study, however, especially using longitudinal designs of at risk samples, will be required to establish fully the existence of these pathways and to characterize the way motivational and cognitive factors interact during development.

Although uncorrelated in the present study, inhibitory deficits and delay aversion act together to influence behavior in some cases. Indeed one might expect such a combination to increase the risk of $\mathrm{AD} / \mathrm{HD}$ and the scale of impairment. One might also expect tests that tap these two constructs to be especially strongly associated with $\mathrm{AD} / \mathrm{HD}$. In this regard, the findings relating to the delay of gratification task are noteworthy. As predicted, this task tapped both inhibitory deficits and delay aversion. Furthermore, it was by far and away the best predictor of $\mathrm{AD} / \mathrm{HD}$ group membership. In fact, supplementary analyses showed that on its own it was able to predict correctly group membership for 82 percent of children $(89$ percent sensitivity and 74 percent specificity). The predictive power of this task was very much greater than either the DAI or the go-no-go inhibition task (each correctly identified 66 
percent of the cases). This result suggests that inhibitory deficits and delay aversion might interact multiplicatively to produce significantly greater problems than would be produced if one or other factor acted alone.

The results from the choice delay task are very similar to those shown with school-aged children and confirm the relevance of the distinction between delay aversion and 'impulsiveness' in AD/HD (Sonuga-Barke et al., 1992). AD/HD children chose 'impulsively' only when this reduced the total delay per trial (under the N-PRD condition). This contrasts with findings from two studies that demonstrated a preference for SS among $\mathrm{AD} / \mathrm{HD}$ children even when overall delay per trial is held constant (Schweitzer \& SulzerAzaroff, 1995). It must be noted, however, that 'impulsiveness' and delay aversion are not exclusive constructs. $\mathrm{AD} / \mathrm{HD}$ children who display impulsiveness (prefer SS on PRD trials) may manifest their delay aversion by an increase in that preference under the N-PRD. Why the $\mathrm{AD} / \mathrm{HD}$ children were not impulsive in the PRD condition of the present study is unclear. One possibility is that impulsiveness is displayed only with longer delays prior to LL.

\section{Clinical implications}

If confirmed, the existence of cognitive and motivational bases of $\mathrm{AD} / \mathrm{HD}$ could have major implications for both diagnosis and treatment. Current phenomenological approaches to diagnosis may need to be supplemented by theoretical approaches that provide insight at the psychological level. This supplementation could involve a greater role for psychological testing in diagnosis or a reframing of diagnostic items so that they take into account the psychological content of symptoms. Identifying the context of behavior may be especially important in the diagnosis of the motivational type of $\mathrm{AD} / \mathrm{HD}$.
Identifying subtypes might help target treatments. Medications that act on particular cortico-striatal circuits might be effective for one but not for the other type. While methylphenidate is relatively non-specific in its action, affecting both executive and reward circuits, atomoxetine (a specific norepinephrine reuptake blocker) increases extracellular dopamine in the pre-frontal cortex while leaving reward circuits relatively unaffected. This medication may therefore be more effective for the cognitive than for the motivational type. Non-pharmacological interventions might also be effectively targeted once psychological types have been identified. For instance, behavioral intervention focused on shaping delay tolerance through desensitization techniques might be of value for the motivational subtype, whereas self control training may be better for the cognitive type.

\section{Limitations of the study}

Although powered to detect relatively small effects $(\eta=.12$. for DAI), the sample size of the current study limited the scope of the analyses that could be performed, as well as the generalizability of the results. Whereas the associations between $\mathrm{AD} / \mathrm{HD}$ and the two psychological factors held after gender, IQ and the presence of conduct problems were controlled, thus exploring interactions between these factors and $\mathrm{AD} / \mathrm{HD}$ status was not possible. Furthermore, there was no opportunity to identify different types of $\mathrm{AD} / \mathrm{HD}$ (motivational, cognitive, or mixed) at the level of the individual child. It will be important to replicate and extend the current findings in a larger sample. Ascertainment for the study was based on a community-based procedure that used only one of a number of possible approaches for the identification of pre-school $\mathrm{AD} / \mathrm{HD}$. It will be important to see if the same pattern of results is seen in samples ascertained using other approaches, including DSM-IV referenced approaches. 


\section{REFERENCES}

Anderson V. 1998. Assessing executive functions in children: Biological, psychological, and developmental considerations. Neuropsychol Rehab 8: 319-349.

Barkley RA. 1997. Behavioral inhibition, sustained attention, and executive functions: Constructing a unifying theory of ADHD. Psychol Bull 121: 65-94.

Barkley RA, Shelton TL, Crosswait C, Moorehouse M, Fletcher K, Barrett S, et al. 2002. Preschool children with disruptive behavior: Three-year outcome as a function of adaptive disability. Dev Psychopathol 14: 45-67.

Barnett R, Maruff P, Vance A, Luk ESL, Costin J, Wood C, Pantelis C. 2001. Abnormal executive function in attention deficit hyperactivity disorder: the effect of stimulant medication and age on spatial working memory. Psychol Med 31: 1107-1115.

Bayliss DM, Roodenrys S. 2000. Executive processing and attention deficit hyperactivity disorder: an appli-cation of the supervisory attentional system. Dev Neuropsychol 17: 161-180.

Berlin L, Bohlin G. 2002. Response inhibition, hyperactivity, and conduct problems among preschool children. J Clin Child Adoles Psychol 31: 242-251.

Campbell SB, Pierce EW, March CL, Ewing LJ, Szumowski EK. 1994. Hard-to-manage preschool boys - symptomatic behavior across contexts and time. Child Dev 65: 836-851

Campbell SB, Szumowski EK, Ewing LJ, Gluck DS, Breaux AM. 1982. A multidimensional assessment of parent-identified behavior problem toddlers. $\mathrm{J}$ Abnorm Child Psychol 10: 569-592.

Cardinal RN, Pennicott DR, Sugathapala CL, Robbins TW, Everitt BJ. 2001. Impulsive choice induced in rats by lesions of the nucleus accumbens core. Science 292: 2499-2501.

Casey BJ, Tottenham N, Fossella J. 2002. Clinical, imaging, lesion, and genetic approaches toward a model of cognitive control. Dev Psychobiol 40: 237-254.

Castellanos FX, Tannock R. Neuroscience of attentiondeficit/hyperactivity disorder: 2002 . The search for endophenotypes. Nat Rev Neurosci 3: 617-628.

Connor DF. Preschool attention deficit hyperactivity disorder: 2002. A review of prevalence, diagnosis, neurobiology, and stimulant treatment. J Dev Behav Pediat 23: S1-S9.

Dalen L. 2002. Eexecutive Functions and Delay
Aversion in Preschool children. Unpub Diss University of Southampton.

De Renzi E, Faglioni P, Savoiardo M. 1966. T he influence of aphasia and of the hemispheric side of the cerebral lesion on abstract thinking. Cortex 2: 399-420.

Espy KA, Kaufmann PM, Glisky ML, McDiarmid MD. 2001. New procedures to assess executive functions in preschool children. Clin Neuropsychol 15: 46-58.

Gardner F, Sonuga-Barke EJS, Sayal K. 1999. Parents anticipating misbehavior: An observational study of strategies parents use to prevent conflict with behavior problem children. J Child Psychol Psychiat 40: 1185-1196.

Giedd JN, Blumenthal J, Molloy E, Castellanos FX 2001. Brain imaging of attention deficit/ hyperactivity disorder. Ann New York Acad Sci 931: 33-49.

Golden M, Montare, A,Bridger W. 1997. Verbal control of delay behavior in two year old boys as a function of social class. Child Dev 48: $1107-$ 1111.

Goodman R. 1997. The strengths and difficulties questionnaire: A research note. J Child Psychol Psychiat 38: 581-586.

Hughes C, White A, Sharpen J, Dunn J. 2000. Antisocial, angry, and unsympathetic: "Hard-tomanage" pre-schoolers' peer problems and possible cognitive influences. I Child Psychol Psychiat 41: 169-179.

Kochanska G, Murray K, Jacques TY, Koenig AL, Vandegeest A. 1996. Inhibitory control in young children and its role in emerging internalization. Child Dev 67: 490-507.

Kuntsi J, Oosterlaan J, Stevenson J. 2001. Psychological mechanisms in hyperactivity: I. Response inhibition deficit, working memory impairment, delay aversion, or something else? J Child Psychol Psychiat 42: 199-210.

Lahey BB, Pelham WE, Stein MA, Loney J, Trapani C, Nugent $\mathrm{K}$, et al. 1998. Validity of DSM-IV Attention-Deficit Hyperactivity Disorder for younger children. J Am Acad Child Adoles Psychiat 37: 695-702.

Mariani MA, Barkley RA. 1997. Neuropsychological and academic functioning in preschool boys with attention deficit hyperactivity disorder. Dev Neuropsychol 13: 111-129.

Reed MA, Pien DL, Rothbart MK. 1984. Inhibitory 
self control in preschool children. Merrill Palmer Quart 30: 131-147.

Reynolds B, de Wit H, Richards JB. 2002. Delay of gratification and delay discounting in rats. Behav Process 59: 157-168.

Robbins TW, Everitt BJ. 1996. Neurobehavioral mechanisms of reward and motivation. Curr Opin Neurobiol 6: 228-236.

Sagvolden T, Aase H, Zeiner P, Berger D. 1998. Altered reinforcement mechanisms in attention deficit/hyperactivity disorder. Behav Brain Res 94: 61-71.

Schweitzer JB, Sulzer-Azaroff B. 1995. Self-control in boys with attention deficit hyperactivity disorder: Effects of added stimulation and time. J Child Psychol Psychiat 36: 671-686.

Solanto MV, Abikoff H, Sonuga-Barke E, Schachar R, Logan GD, Wigal T, et al. 2001. The ecological validity of delay aversion and response inhibition as measures of impulsivity in $\mathrm{AD} / \mathrm{HD}$ : a supplement to the NIMH multi-modal treatment study of AD/HD. J Abnorm Child Psychol 29: 215-28.

Sonuga-Barke EJ. 1994. On dysfunction and function in psychological theories of childhood disorder. $J$ Child Psychol Psychiat 35: 801-815.

Sonuga-Barke EJ. 2002. Psychological heterogeneity in $\mathrm{AD} / \mathrm{HD}-\mathrm{a}$ dual pathway model of behaviour and cognition. Behav Brain Res 130: 29-36.

Sonuga-Barke EJ. 2003. The dual pathway model of $\mathrm{AD} / \mathrm{HD}$ : an elaboration of neuro-developmental characteristics. Neurosci Biobehav Rev 27: 593604.

Sonuga-Barke EJ, Dalen L, Daley D, Remington B. 2002. Are planning, working memory, and inhibition associated with individual differences in preschool ADHD symptoms? Dev Neuropsychol 21: 255-272.

Sonuga-Barke EJ, Daley D, Thompson M. 2002.
Does maternal ADHD reduce the effectiveness of parent training for preschool children's ADHD? J Am Acad Child Adolesc Psychiatry 4: 696-702.

Sonuga-Barke EJ, Daley D, Thompson M, LaverBradbury C, Weeks A. 2001. Parent-based therapies for pre-school attention-deficit/hyperactivity disorder: A randomized controlled trial with a community sample. J Am Acad Child Adolesc Psychiatry 40: 402-408.

Sonuga-Barke EJS, Daley D, Thompson M, Swanson J. 2003. Preschool ADHD: exploring uncertainties in diagnostic validity and utility, and treatment efficacy and safety. Expert Rev Neurotherapeutics 3: 465-476.

Sonuga-Barke EJ, Lamparelli M, Stevenson J, Thompson M, Henry A. 1994. Behaviour problems and pre-school intellectual attainment: the associations of hyperactivity and conduct problems. J Child Psychol Psychiatry 35: 949-960.

Sonuga-Barke EJ, Thompson M, Stevenson J, Viney D. 1997. Patterns of behaviour problems among pre-school children. Psychol Med 27: 909-918.

Sonuga-Barke EJ, Taylor E, Sembi S, Smith J. 1992. Hyperactivity and delay aversion. I. The effect of delay on choice. J Child Psychol Psychiatry 33: 387-398.

Taylor E, Sandberg S, Thorley G, Giles S. 1991. The Epidemiology of Childhood Hyperactivity. London, UK: Oxford University Press.

Tripp G, Alsop B. 2001. Sensitivity to reward delay in children with attention deficit hyperactivity disorder (AD/HD). J Child Psychol Psychiatry 42: 691-698.

Wilens TE, Biederman J, Brown S, Tanguay S, Monuteaux MC, Blake C, et al. 2002. Psychiatric co-morbidity and functioning in clinically referred preschool children and school-age youths with ADHD. J Am Acad Child Adoles Psychiatry 41: 262-268. 

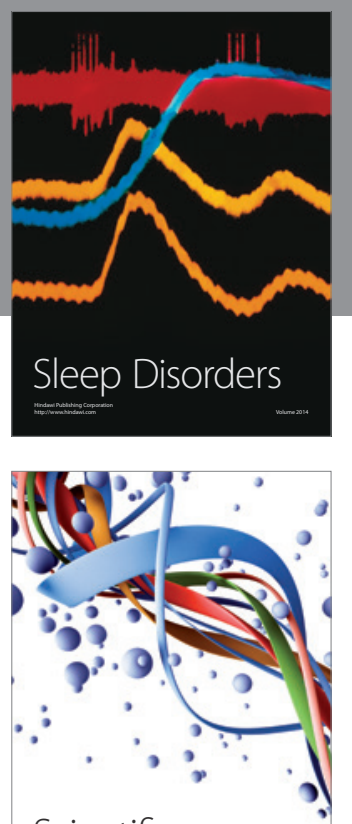

Scientifica
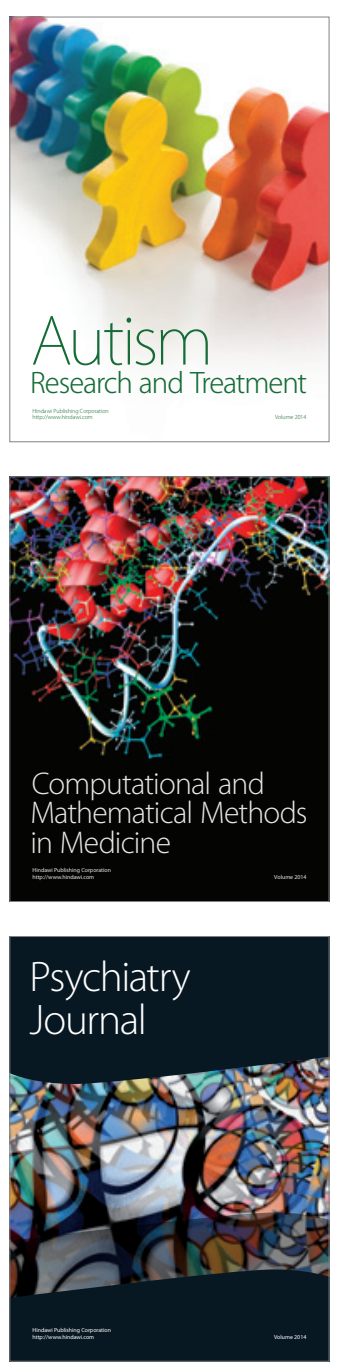
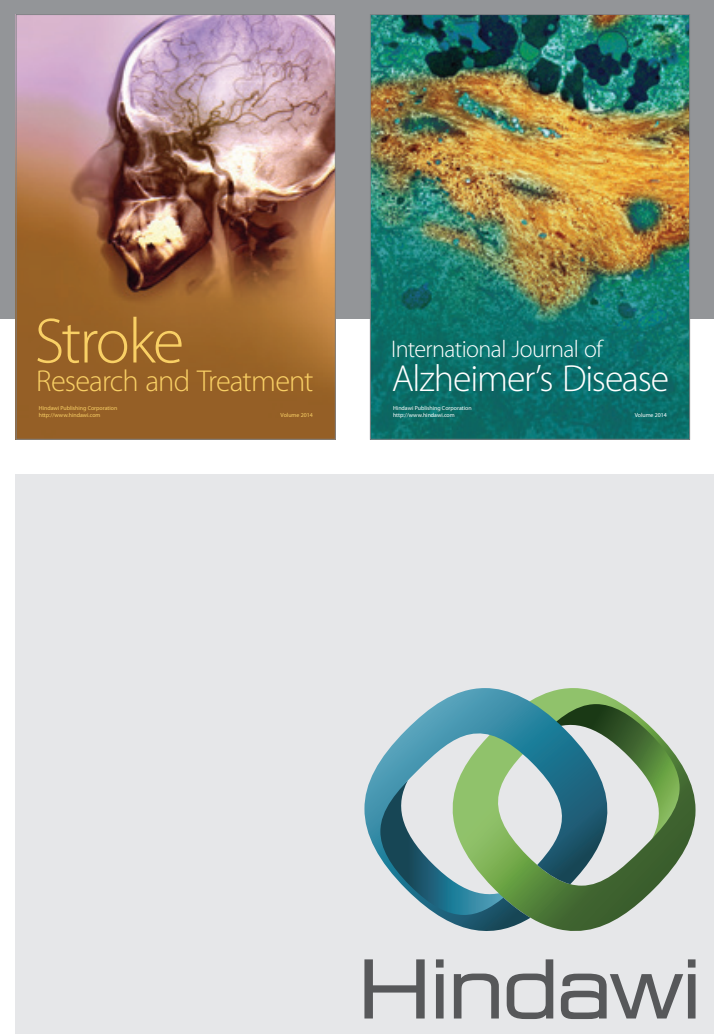

Submit your manuscripts at

http://www.hindawi.com
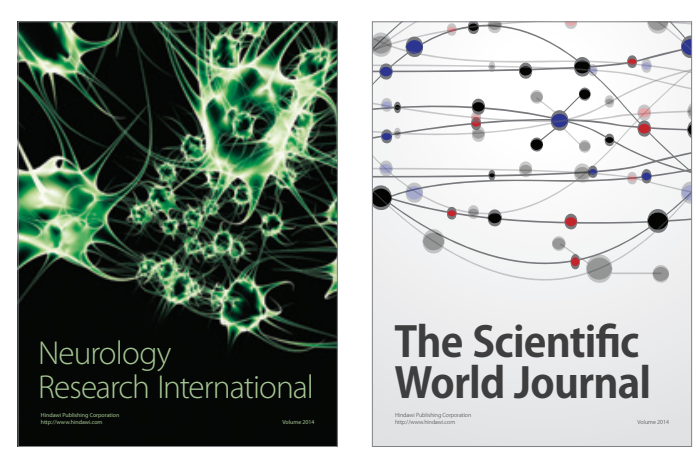

The Scientific World Journal

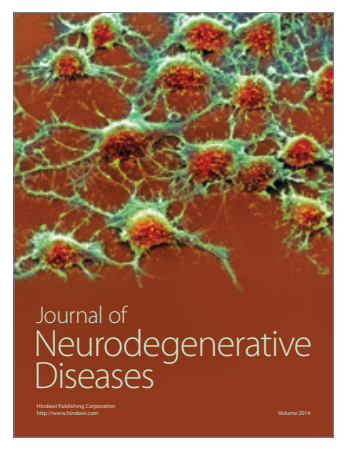

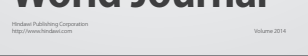

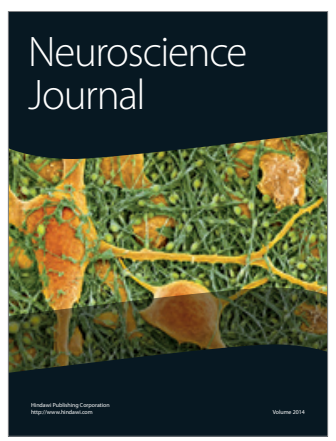

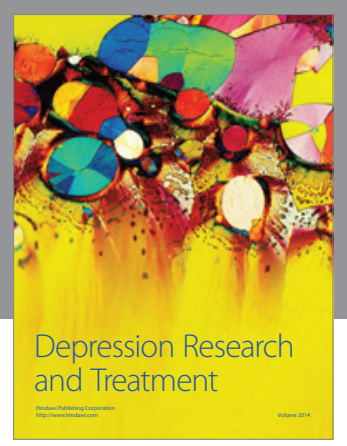
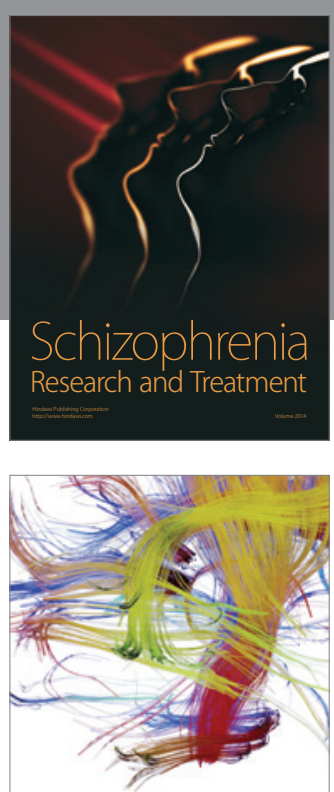

Brain Science

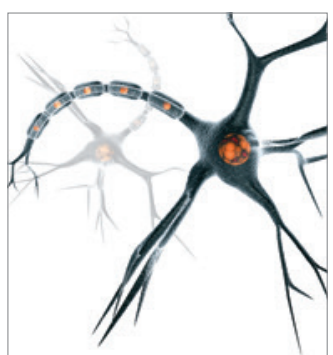

Neural Plasticity
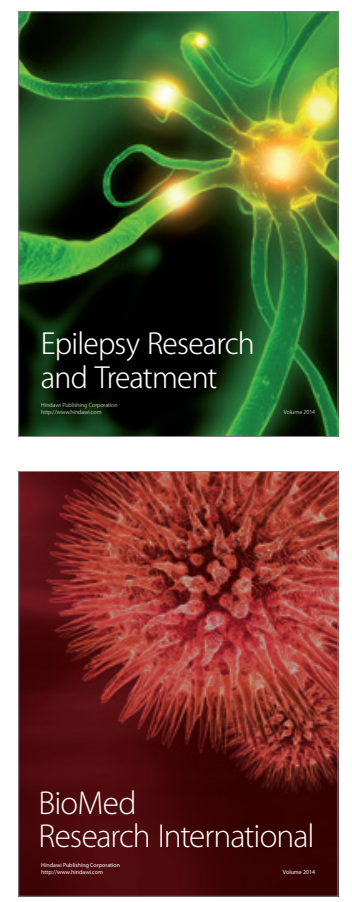

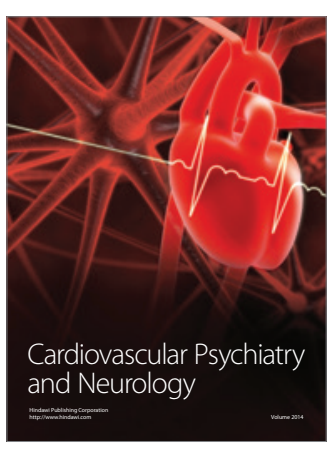

Parkinson's

Disease
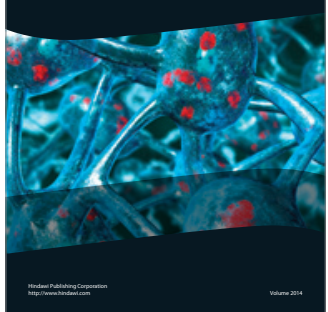